REVISTA DE DERECHO UNED, núm. 1, 2006

\title{
REFLEXIONES ACERCA DEL PRINCIPIO ALTERUM NON LAEDERE A LA LUZ DE UN SUPUESTO DE RESPONSABILIDAD EXTRACONTRACTUAL
}

\author{
Laura Ostos Palacios ${ }^{1}$
}

Ponente: Excmo. Sr. D. Alfonso Villagómez Rodil

Disposiciones legales citadas: Artículos 1.4, 350, 353 y 544 del Código Civil. Artículos 359, 1.692. 3, 4 y 5, y 1.715 de la Ley de Enjuiciamiento Civil

Fuentes: D.1,1,10,1 e I.1,1,3

Jurisprudencia citada: Sentencias de 13 de octubre de 1990, 16 de julio y 1 de octubre de 1992

Fallo: No ha lugar al recurso

\section{HECHOS:}

La demandante interpuso un juicio declarativo de menor cuantía contra la Comunidad de Propietarios de una finca de Barcelona, ante las frecuentes inundaciones que provocaban atascos y embocamientos, así como afectaban al albañal en su uso y tramo común. De modo que, al verse reducido el diámetro del desagüe, como consecuencia de los residuos y detergentes vertidos, se producían constantes daños. En el caso de autos, consta que, al levantarse el edificio de la comunidad demandada, en vez de colocar un nuevo colector, aprovecharon la existencia del antiguo y conectaron a éste todas las tuberías de bajantes residuales.

\footnotetext{
1 Profesora Asociada del Departamento de Derecho romano de la UNED
} 
La demanda fue tramitada ante el Juzgado de primera instancia número doce de Barcelona. Se dictó sentencia estimatoria que condenaba a la Comunidad de Propietarios a la realización de ciertas obras con el fin de evitar la persistencia de los daños. Esta sentencia fue recurrida por la demandada y la Audiencia Provincial de Barcelona dictó resolución confirmando la sentencia de instancia. A su vez, la Comunidad de propietarios interpuso recurso de casación contra la sentencia recaída en apelación. El Tribunal Supremo desestima el recurso de conformidad con los argumentos jurídicos que se relacionan a continuación ${ }^{2}$.

\section{FUNDAMENTOS DE DERECHO 3 :}

PRIMERO.— «Los dos primeros motivos han de ser estudiados conjuntamente, al converger en la impugnación que denuncian de haberse producido error en la apreciación de la prueba, conforme al número $4{ }^{\circ}$ del artículo procesal 1.692, señalando, al efecto, como documentos que expresan error, la escritura pública de fecha 3 de diciembre de 1957, su representación gráfica y certificación registral negativa de existencia de servidumbre de desagüe de aguas residuales a favor de finca interior (trasera) sobre la otra exterior, localizadas, ambas, en la calle Maestro Falla número 31 de Barcelona. Mediante dicho documento público, don Guillermo Villavecchia Ricart vendió a don Eduardo Cros Rojas y Antonio Mas Brosas, una porción de terreno de 357,41 metros cuadrados, que segregó de la finca matriz. En el solar enajenado (finca exterior) se construyó un bloque de viviendas, para el que acciona como recurrente casacional, su Comunidad de Propietarios, quedando el resto del inmueble (finca interior) de la propiedad de dicho enajenante, donde había levantado, con anterioridad, un garaje, actualmente arrendado para almacén de editorial y que practica por dos pasillos su entrada y salida a la vía pública.

Constituyen antecedentes necesarios, como datos fácticos probados y firmes, que el referido don Guillermo Villavecchia Ricart transmitió a su esposa doña Mercedes Fernández Adame (actora del pleito y parte recurrida) -en régimen matrimonial catalán de separación de bienes-, a medio de escritura pública de 19 de agosto de 1966, la referenciada finca interior con la construcción del local referido.

${ }^{2}$ La sentencia se transcribe de la publicada en la colección legislativa. Jurisprudencia civil (Número 1.100) B.O.E. Madrid 1995, 1242-1246.

${ }^{3}$ En cursiva se destaca la doctrina de la Sentencia. 
La escritura de venta reseñada, efectivamente, no contiene declaración alguna respecto al desagüe controvertido, el que consiste en que en dicha finca interior-trasera, para dar salida a las aguas pluviales y residuales y cuando se integraba en la misma propiedad con el solar segregado, se instaló un albañal de desagüe para el exclusivo uso de la misma. No obstante, al levantarse el edificio de la Comunidad, sus propietarios, a medio de la constructora, en vez de colocar un nuevo colector, lo que se presenta como lo más correcto, aprovecharon la existencia del antiguo, al que conectaron todas las tuberías de bajantes de aguas residuales de las viviendas, lo que revela por sí el conocimiento adecuado y la existencia del referido albañal, que discurre subterráneo y que pasó a ser único y común para la finca interior y la exterior. A tales efectos se aportó prueba eficiente en este sentido que no fue desconocida ni impugnada de contrario, y que hay que referir al informe acompañado con la demanda y prueba confesional practicada que lo ratificó.

De esta manera, aunque la escritura de enajenación no refleja el desagüe discutido, el mismo se presenta como correspondiente a una realidad y situación fáctica preexistente, aceptada y conocida e, incluso, aprovechada por la Comunidad que recurre, pues, en todo caso, no se trata de una canalización oculta o subrepticia, sino subterránea y en funcionamiento, lo que son cuestiones distintas.

La sentencia combatida centra la controversia con loable acierto y precisión jurídica, pues, efectivamente, no se discute la existencia o no de una posible servidumbre, ya que no se planteó, sino más bien la adopción de las medidas necesarias para evitar la causación de daños que afectan a la propiedad de la actora del pleito, por consecuencia de las frecuentes inundaciones que provocan los atascos y embocamientos que afectan al albañal en su uso y tramo común, al verse reducido su diámetro por consecuencia de los deshechos, residuos jabonosos y detergentes que aporta al mismo la Comunidad de Propietarios demandada, lo que conforman hechos debidamente acreditados y se presentan incólumes en casación.

Los motivos perecen, ya que, no obstante lo expuesto, la parte recurrente, que no aportó escrito de contestación a la demanda, aprovecha los mismos para llevar a cabo su impugnación opositora a la demanda principal, lo que no resulta procedente, al tratar, de esta manera, de desvirtuar la controversia casacional por vías argumentales sobre el fondo del litigio, planteando cuestión nueva respecto a la negación de la pretendida servidumbre, que sólo se presenta en su aspecto de situación de hecho mantenida, pero no en la dimensión de 
su existencia y eficacia jurídica como tal; lo que, en todo caso, debió de llevar a cabo en la instancia, pues bien pudo oportunamente contestar, y, en su caso, reconvenir, si a sus derechos así le convenía.»

SEGUNDO.- - «Se argumenta, en el tercero de los motivos, que concurre situación de incongruencia decisoria, por infracción del artículo 359 de la Ley Procesal Civil, con residencia en el número $3^{\circ}$ de su precepto 1.692 .

Se sostiene, al efecto, que la sentencia resuelve una cuestión que no formuló la recurrida, cual es la titularidad del albañal en disputa, en cuanto se argumenta, conforme ya queda expuesto, que el anterior propietario construyó tal desagüe para dar salida a las aguas provenientes del tejado y pequeño aseo del local dedicado a garajes, conectándolo al alcantarillado público, a cuyo efecto corre por el subsuelo del primitivo solar y ahora finca construida exterior.

La resolución atacada deja bien explicado que lo que se debate, exclusivamente, es la viabilidad de una acción que se ejercita en razón a las consecuencias dañosas derivadas de la conexión practicada, y se postula, decidida y únicamente, que la recurrente, en razón a su actuar de conveniencia e indudable provecho y utilidad, realice las obras necesarias a evitar los daños y perjuicios que afectan a la finca trasera, generadora del albañal, por razón de la sobrecarga en el desagüe que ha producido dicha Comunidad.

Se parte de una situación permanencial, cuya consideración jurídica, de ser constitutiva de servidumbre o no, queda sin juzgar, conforme se explicita, y así no la refleja el fallo decisorio; con lo cual la pretendida incongruencia no se presenta concurrente.

Es incongruente la sentencia que declara o concede algo distinto a lo peticionado o deja de resolver alguna cuestión alegada, lo que no se aplica cuando, en vía casacional, se trata de aportar propios fundamentos fuera del ámbito del proceso y se especula con los que integran el cuerpo jurídico de la sentencia combatida, pues la incongruencia no deriva, según el artículo 359 de la Ley de Enjuiciamiento Civil, de los argumentos empleados por el Tribunal de la instancia para fundamentar su fallo (Sentencias de 13 octubre $1990^{4}$ y 16 julio $^{5}$ y 1 octubre $1992^{6}$ ), que, en todo caso, seguía siendo negativo para la parte recurrente, ya que el cuerpo dispositivo de las sentencias es el

${ }^{4}$ Vid. RJ 1990/7862.

5 Vid. RJ 1992/6615.

6 Vid. RJ 1992/7514. 
que opera como ley para los que litigan, y ha de tener la eficacia suficiente para dejar resueltos los puntos que conformaron el debate procesal.»

TERCERO.- - «a Comunidad recurrente, a medio de denuncia de infracción del artículo 350 del Código Civil, reivindica, en su motivación cuarta, la propiedad extensiva respecto al conductor de aguas de referencia, en relación al artículo 353, por vía de la accesión, con lo que se viene a aportar cuestión nueva, al no haberse contestado a la demanda, y tal tema no integró adecuada materia contradictoria del pleito y, consecuentemente, careció de toda corroboración probatoria. Con todo ello, se hace oposición frontal y se margina lo que ha quedado debida y suficientemente demostrado, en cuanto a que el colector fue realizado por el anterior dueño de la totalidad de la finca, y, por tanto, en terrenos de su propiedad, y los titulares del edificio, que no lo construyeron, se limitaron a empalmar al mismo todas las bajantes de desagüe, utilizando, así, en su beneficio, lo ya existente y no incorporado con posterioridad. De esta manera, reconocen y admiten la obra ajena que afectaba al subsuelo de la casa levantada mucho más tarde.

El motivo se desestima.»

CUARTO.- «En el último motivo, se lleva a cabo impugnación de la declaración que contiene la sentencia recurrida respecto a que los gastos de reparación del albañal o construcción de uno nuevo serán de cuenta de la Comunidad de Propietarios que recurre, argumentando concurrir infracción del artículo 544 del Código Civil, en razón a que para los supuestos de servidumbres declaradas y compartidas -lo que no es objeto del litigio, como quedó bien explicado-, la contribución a los gastos de su mantenimiento y uso se distribuirá entre los dueños de los predios dominante y sirviente.

La sentencia de apelación aceptó, en este punto, las razones jurídicas de la dictada en la primera instancia, que no aplicó al referido precepto. Al contrario, partiendo, como hecho que deviene probado firme, que se ha producido un uso abusivo por sobrecarga en el colector de salida de aguas, en razón al vertido de productos de consumo familiar, imputable, exclusivamente, a la Comunidad de Propietarios, ello causó la reducción en su diámetro y disponibilidad del uso normal, con lo que los consecuentes daños y perjuicios, materializados por las frecuentes inundaciones que han afectado y afectan a la finca de la recurrida, han de ser de cuenta y cargo de la parte recurrente, por su actuar activo y omisivo, lo que hace aplicable los principios generales de Derecho (artículo $1.4^{\circ}$ del Código Civil), "Et que ocassionem praestat, damnun fecisse videtur»-Paulo(El que da ocasión se entiende, también, que causa el daño); "Commodo 
ferens, incommoda et onera, sustinere debet»-Decio-- (El que está a las ventajas, debe también soportar las desventajas y las cargas); $y$, "alterum non laedere», conduciendo todo ello a la claudicación del motivo.»

QUINTO.- «La no estimación del recurso da lugar a que las costas correspondientes al mismo sean de cuenta de la parte litigante, que lo formalizó, conforme al artículo 1.715 de la Ley de Enjuiciamiento Civil, con pérdida del depósito constituido.»

\section{COMENTARIO:}

Se ha seleccionado esta sentencia ${ }^{7}$ como muestra de la vigencia y relevancia de los principios procedentes del derecho romano en la jurisprudencia actual. En particular, tenemos en cuenta uno de los recogidos por esta sentencia del Tribunal Supremo, alterum non laedere, que se considera, por la mejor doctrina, como el principio general por excelencia ${ }^{8}$.

Este principio es enunciado en su orígen por Ulpiano: iuris preacepta sunt haec: honeste vivere, alterum non laedere, suum cuique tribuere. La traducción más habitual es la siguiente: los preceptos del Derecho son estos: vivir honestamente, no hacer daño a otro, atribuir a cada uno lo suyo'. Reinoso Barbero llama la atención sobre la similitud que existe entre el principio enunciado por Ulpiano en Digesto 1,1,10,1 (Ulpianus libro primo regularum) y el pensamiento que este mismo jurista refleja en Digesto 39,3,1,11 (Ulpianus libro quinquagensimo tertio ad edictum) ${ }^{10}$.

Este texto, extractado por los compiladores del libro primero de los Instituta del mismo jurista, se recoge en el Título 1,1 de Digesto, de rúbrica "De iustitia et iure» y en las Instituciones de Justiniano. Volvemos a encontrarlo en el derecho medieval y se reproduce en la Partida $3,1,3^{11}$. Paulatinamente se incluye en distintos textos legales

7 Sentencia de 5 de diciembre de 1994 de la Sala Primera del Tribunal Supremo.

8 Vid. REINOSO BARBERO, F., Los principios generales del Derecho en la jurisprudencia del Tribunal Supremo, Madrid 1988, 50.

9 DOMINGO R. y RODRÍGUEZ-ANTOLÍN B., Reglas juridicas y aforismos, Pamplona 2000, 74.

${ }_{10}$...prodesse enim sibi unusquisque, dum alii non nocet, non prohibetur...

11 Segund departieron los Sabios antiguos, Justicia tanto quiere dezir, como cosa en que se encierran todos los derechos, de qual natura quier que sean. Elos mandamientos de la Justicia, e del Derecho son tres. El primero es, que orne biva honestamente, quanto en si. El segundo, que non faga mal nin daño a otro. El tercero, que de su derecho a cada vno. 
pertenecientes a la época intermedia y, por fin, aparece en los primeros pronunciamientos del Tribunal Supremo ${ }^{12}$.

Si a la aplicación del principio neminem laedere añadimos los otros señalados por el Tribunal Supremo en esta sentencia —et que ocassionem praestat, damnun fecisse videtur ${ }^{13}$ y commodo ferens, incommoda et onera, sustinere debet ${ }^{14}$-, aún cobra mayor sentido la afirmación de la sucesiva e incesante presencia «del Derecho romano en el Derecho español, ya que éste no es, ni mucho menos, un supuesto aislado, sino un ejemplo cualquiera de cómo una regula iuris se ha convertido en un principio general del Derecho» ${ }^{15}$. Los principios jurídicos expuestos por la Sala del Tribunal Supremo, además del que se está analizando, son obra de Paulo y Decio. Paulo, jurista perteneciente a la misma escuela que Ulpiano, contemporáneo de éste y, junto a él, de los más destacados juristas clásicos romanos, enuncia el primero de ellos, y Felipe Decio, glosador y comentarista del Derecho común medieval, comentador de las reglas de Digesto ${ }^{16}$, se dedica, entre otras tareas, a perfilar y abreviar aforismos jurídicos romanos y canónicos.

En la sentencia que se comenta, el juzgador se apoya, en el principio alterum non laedere para desestimar el recurso planteado por la Comunidad de Propietarios demandada como causante del daño, y en sus fundamentos afirma su valor y rango como principio general del Derecho, fuente, por tanto, del ordenamiento jurídico español ${ }^{17}$.

Ese daño o pérdida sufrido por la demandante en el caso de autos, ha de ser resarcido por el agente causante, tal y como contempla el ar-

12 Para el estudio en profundidad de su evolución histórica, vid. REINOSO BARBERO, Los principios generales del Derecho en la jurisprudencia del Tribunal Supremo cit.

${ }_{13}$ D. 9,2,30,3 (Paulus libro vicensimo secundo ad edictum): In hac quoque actione, quae ex hoc capitulo oritur, dolus et culpa punitur: ideoque si quis in stipulam suam vel spinam comburendae eius causa ignem immiserit et ulterius evagatus et progressus ignis alienam segetem vel vineam laeserit, requiramus, num imperitia eius aut neglegentia id accidit. nam si die ventoso id fecit, culpae reus est (nam et qui occasionem praestat, damnum fecisse videtur): in eodem crimine est et qui non observavit, ne ignis longius procederet. El jurista, una vez más, constata la doctrina seguida por la jurisprudencia al entender que el que da ocasión, también causa el daño.

14 DECIO: El que está a las ventajas, debe también soportar las desventajas y las cargas.

15 REINOSO BARBERO, Los principios generales del Derecho en la jurisprudencia del Tribunal Supremo, cit.

${ }_{16}$ Philippus Decius in titulum Digesti de Regulis iuris cum additionibus, Lyon 1581.

17 Art. 1.4 Código civil: «Los principios generales del Derecho se aplicarán en defecto de ley o costumbre, sin perjuicio de su carácter informador del ordenamiento jurídico.» 
tículo 1.089 del Código civil ${ }^{18}$, y sustenta la sentencia cuando afirma que no se discute la existencia o no de una servidumbre, sino la adopción de medidas correctoras para evitar la causación de daños.

En resumen, la sentencia se ocupa de un supuesto de responsabilidad civil extracontractual como fuente de obligaciones y aplica, como fuente del ordenamiento jurídico español, los principios generales de Derecho que se acaban de mencionar, procedentes, la mayoría de ellos, del Derecho romano. Como consecuencia de la aplicación de estos principios, abogamos también por la calificación de la responsabilidad civil como responsabilidad aquiliana o extracontractual, cuyo fundamento se encontraría en la lex Aquilia.

En efecto, la lex de damno, datada aproximadamente en el año 286 a.C., fue un plebiscito del tribuno Aquilio que derogó las leyes precedentes que trataban del daño injusto, si bien dejó en vigor otras acciones de carácter privado que tenían por objeto la reclamación o indemnización del daño inflingido ${ }^{19}$. El ilícito aquiliano comprendía toda clase de comportamientos dolosos y negligentes ${ }^{20}$ que comportaran la producción de un damnum.

En conclusión, y sobre el caso concreto que analizamos, podemos señalar que los contenidos del derecho romano, sus «materiales, sus instituciones, sus reglas y principios, y no sólo su espíritu» ${ }^{21}$ están cristalizados en la mayoría de los Códigos civiles europeos y, en particular, en el Código civil español. Con estas líneas se ha puesto de manifiesto, una vez más, la evidente actualidad y vigencia del derecho romano en el derecho civil, la jurisprudencia y en el futuro Código civil europeo que debería derivar de los principios comunes a los ordenamientos de los Estados miembros ${ }^{22}$.

18 Sobre el damnum d'ORS, A. señala que consiste en «...la pérdida sufrida, lo que se puede traducir aceptablemente por 'daño', pero puede significar, como en la expresión (damnum decidere), no la pérdida causada al que sufrió el delito, sino la que debe imponerse como pena al autor del delito». Derecho PrivadoRromano, Pamplona 2004, (373 n. 1

19 GARCÍA GARRIDO, M.J., Derecho Privado Romano. Casos. Acciones. Instituciones, Madrid 2005, 226.

${ }_{20}$ Para el estudio de sus elementos vid. GARCÍA GARRIDO, Derecho Privado Romano. Casos. Acciones. Instituciones, cit. Para otros aspectos complementarios sobre la noción de culpa vid. MARTÍN MINGUIJÓN, A.R., Fórmulas reconstruídas y acciones in factum conceptae, Madrid 2001, 264.

${ }^{21}$ FERNÁNDEZ DE BUJÁN FERNÁNDEZ, F., Sistema contractual romano, Madrid 2004, 481.

22 Vid. FERNÁNDEZ DE BUJÁN FERNÁNDEZ, F. Sistema contractual romano, cit., $482-491$. 